\title{
Reducing unsafe menstrual regulation through medication in Bangladesh
}

\author{
Ubaidur Rob \\ Population Council \\ Ismat Ara Hena \\ Nargis Sultana \\ Population Council \\ Md. Irfan Hossain \\ Population Council \\ Reena Yasmin
}

See next page for additional authors

Follow this and additional works at: https://knowledgecommons.popcouncil.org/departments_sbsr-rh

Part of the Demography, Population, and Ecology Commons, Family, Life Course, and Society Commons, International Public Health Commons, Maternal and Child Health Commons, Obstetrics and Gynecology Commons, and the Women's Health Commons How does access to this work benefit you? Let us know!

\section{Recommended Citation}

Rob, Ubaidur, Ismat Ara Hena, Nargis Sultana, Md. Irfan Hossain, Reena Yasmin, Tapash Ranjan Das, and Farid Uddin Ahmed. 2014. "Reducing unsafe menstrual regulation through medication in Bangladesh," STEP UP Policy Brief. Dhaka: Population Council. 


\section{Authors}

Ubaidur Rob, Ismat Ara Hena, Nargis Sultana, Md. Irfan Hossain, Reena Yasmin, Tapash Ranjan Das, and Farid Uddin Ahmed 


\section{POLICY BRIEF}
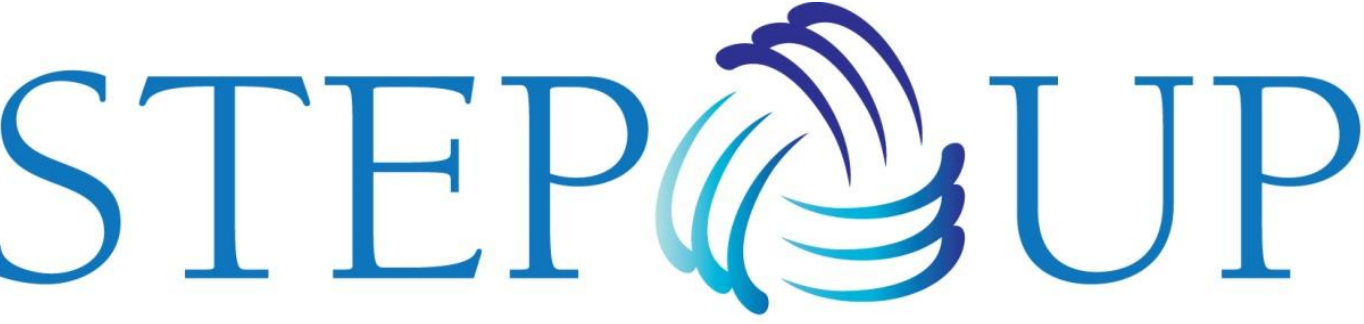

STRENGTHENING EVIDENCE FOR PROGRAMMING ON UNINTENDED PREGNANCY

May 2014

STEP UP generates policy-relevant research to promote an evidencebased approach for improving access to family planning and safe abortion.

We work in Bangladesh, northern India, Ghana, Kenya, and Senegal.

Population Council Coordinating Partner

African Population and Health Research Center icddr,b

London School of Hygiene and Tropical Medicine

Marie Stopes

International

Partners in Population and Development

Funded by

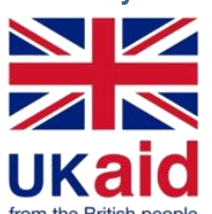

\section{REDUCING UNSAFE MENSTRUAL REGULATION THROUGH MEDICATION IN BANGLADESH}

Despite the availability of effective modern contraceptive methods in Bangladesh, the number of unsafe menstrual regulations is increasing each year, resulting in increased risk of maternal morbidity.

Menstrual regulation (MR) is a medical method of safely establishing non-pregnancy after a missed period. In Bangladesh, MR is typically conducted using manual vacuum aspiration (MVA). In 2010, approximately 653,000 MRs were performed in Bangladesh.

However, MR using MVA carries both health and social risks:

- $\quad$ Stigma and the fear of their situation being disclosed to their community often lead women to turn to illegal measures for abortions that are ineffective, harmful, and life-threatening.

- Studies suggest that unsafe MVA performed by unskilled providers in unhygienic conditions results in over one-third of women suffering postMVA complications.

- Statistics from selected NGO facilities that provide postabortion care services indicate that $25-48 \%$ of women who visited these facilities requested treatment for post-MVA complications (Causes included poor service quality, lack of infection control, and unskilled individuals providing unsafe MVA).

\section{Why is Menstrual Regulation through Medication important?}

Menstrual Regulation with Medication (MRM) is a non-invasive, safe alternative to MVA that is approved in Bangladesh but not yet widely available. By increasing access to this simple and safe MR option, women's morbidity due to MR in Bangladesh could be significantly decreased.

\section{CONCLUSIONS}

- It is feasible and safe to introduce Menstrual

Regulation with Medication in Bangladesh

- Women receiving MRM were satisfied with their quality of care.

\section{RECOMMENDATIONS}

The Ministry of Health and Family Welfare, along with its partners, must:

- In preparation for introducing MRM nationwide, plan a scale-up strategy for phasing in services.

- Implement services first in urban health facilities such as Maternal and Child Welfare Centres (MCWCs) and gradually expand to rural areas.

- Simultaneously, implement a comprehensive training program to train all public sector MR service providers.

- Provide adequate supervision so as to ensure the quality of services.

- Revise and update the management information system to include MRM information.

- Ensure that the requisite medications are routinely supplied to all facilities providing MRM services. 


\section{About this study}

\section{The Population Council and Marie Stopes Bangladesh, in collaboration with the Directorate General of Family Planning and with funding from the World Health Organisation, tested the feasibility of introducing MRM in Bangladesh and assessed the acceptability of providing MRM using the combination drug regimen Mifepristone and Misoprostol in urban and rural public health facilities.}

An 18-month operations research study was conducted from January 2012 to June 2013. Health facilities were selected with high numbers of MR clients and available trained service providers. All women who visited the 13 health facilities for MR services between October 2012 and May 2013 were invited to participate in the study.

All women were counseled by trained service providers about the advantages, disadvantages, and side effects of MR and given a choice between MVA and MRM to regulate menstruation. Clients selecting MRM had the option of taking the second dose-Misoprostol $800 \mathrm{mcg}-$ at the health facility or at home after 24-48 hours.

- Of the 2,976 women who visited the health facilities seeking MR services 63 percent $(1,882)$ selected MRM services.

- Using simple random sampling, information was collected from 836 MRM acceptors and 44 service providers to assess the feasibility and outcomes of the procedure.

- Women who self-administered the second dose were educated on the correct technique for taking the drug, possible side effects, and were given clear instructions to return to the facility or seek immediate medical attention from the call center if they experienced heavy or prolonged vaginal bleeding, sever cramping, fever, chills or malaise lasting more than six hours, any abnormal vaginal discharge, severe abdominal pain, or nausea.

- Women were asked to return to the facility within 10-14 days after taking the second dose for a bimanual pelvic examination to confirm completeness of the MRM procedure.

\section{Results}

- Nearly all providers determined the last menstrual period and 70 percent took a menstrual history. The overall quality of services provided at these health facilities was high.

- Almost all MRM acceptors (97 percent) reported that they would suggest MRM to their friends and relatives; 95 percent would refer a friend to the same facility.

- The vast majority (92\%) of women returned to the facility for the examination to confirm procedure completion.

- One in five clients experienced a side effect (commonly nausea) after taking Mifepristone (first dose), although less than half of these women required medication or further treatment for the side effect.

- Of the 71 women (5\%) who experienced incomplete MRM, 59 received MVA and 12 were referred for dilation and curettage (D\&C) services to complete the procedure.

- The most frequently discussed contraceptive methods during follow-up visits were oral contraceptive pills (77\%) followed by IUDs and condoms. Findings suggest that 69 percent of MRM clients accepted oral pills and 12 percent did not accept any form contraception while 19 percent selected other shortacting methods.

\section{Conclusions}

This study demonstrates that is feasible and safe to introduce MRM in Bangladesh in rural and urban public health facilities. Given the choice, almost two-thirds of women preferred MRM to MVA and women receiving MRM reported being satisfied or very satisfied with their quality of care. It is recommended that the Ministry of Health and Family Welfare (MOHFW) and its partners work together to train providers and to procure the medical commodities to introduce MRM as an option for menstrual regulation in health facilities nationwide.

\footnotetext{
Suggested citation

Rob, Ubaidur, Ismat Ara Hena, Nargis Sultana, Md. Irfan Hossain, Reena Yasmin, Tapash Ranjan Das, and Farid Uddin Ahmed. 2014. "Introducing Menstrual Regulation with Medication in Bangladesh," STEP UP Policy Brief, May 2014. Dhaka: Population Council.
} 